Leser der MMW können sich mit allen Fragen zur Abrechnung und Praxisführung an Helmut Walbert, Facharzt für Allgemeinmedizin, Würzburg, wenden. Sie erreichen ihn jeden Donnerstag von 13 bis 15 Uhr unter der kostenlosen Rufnummer (0800) 2379830 oder per E-Mail: w@lbert.info.
Helmut Walbert

Allgemeinarzt, Medizinjournalist und Betriebswirt Medizin

\title{
Was kann ich dafür verlangen?
}

Frage von Dr. H.P., Hausarzt-Internist, KVWL:

Meine Privatpatienten, aber auch Kassenpatienten wollen immer häufiger Kopien von den erhobenen Befunden oder den Arztbriefen der Kollegen. Wie werden Kopien von Befunden, Arztbriefen usw. abgerechnet?

Antwort: Grundsätzlich sind diese Kosten weder im Bereich der Privatpatienten noch bei Kassenpatienten zulasten der jeweiligen Versicherung abzurechnen. Für diese Kosten ist dem Patienten eine entsprechende Erstattung abzuverlangen. So verlangt es sowohl die Berufs- als auch die Gebührenordnung. Demnach ist die GOÄ zuständig.

Es gibt allerdings keine eigene Gebührenordnungsposition für die Leistung „Fotokopie“, wie sie hier wohl gemeint ist. Die Kosten fallen unter $§ 10$ der GOÄ „Ersatz von Auslagen“.

Meine Empfehlung: Legen Sie in Ihrer GOÄ-Datenbank eine Gebührenposition „Fotokopie“ an und hinterlegen Sie den
Kostensatz, der in einem normalen Copyshop anfälllt, zum Beispiel 20 Cent.

Nicht infrage kommt die GON 96 ,Schreibgebühr, je Kopie“, 3 Punkte, € o,17, einfach. Es ist keine Steigerung erlaubt, da es sich hier um Kostenersatz handelt. Diese GOP ist nämlich leider nur im Zusammenhang mit den GOP 80 oder GOP 85, schriftliche gutachterliche Äußerung abrechenbar. Diese Position gibt aber einen guten Hinweis auf die Bewertungshöhe.

Helmut Walbert .

\section{Praxismiete unberechtigt erhöht?}

\section{Vermieter muss die Anwaltskosten zahlen!}

— Erhöht ein Vermieter einfach die Miete für die Praxisräume, obwohl dies im Vertrag nicht vorgesehen ist, muss er die Anwaltskosten tragen, die dem Arzt dadurch entstanden sind.

Im vorliegenden Fall hatte der Vermieter dem Arzt eine Mieterhöhung angekündigt. Der Arzt schaltete vorsorglich einen Anwalt ein, der die Berechtigung der Mieterhöhung verneinte. Die Vermieterin nahm zwar von der Mieterhöhung Abstand, wollte aber die Anwaltskosten des Arztes in Höhe von 150 Euro nicht übernehmen. Nachdem die Vermieterin die Rechnung des Arztes über 150 Euro ignorierte, zog dieser den Betrag von der nächsten Mietzahlung ab. Das war der Vermieterin zu viel, sie reichte Klage ein.
Die Richter des Amtsgerichts Spandau zeigten der Vermieterin allerdings die Rote Karte. Grundsätzlich sehe das Gesetz keine Erhöhung der Miete bei gewerblichen Räumen vor. Diese könne sich nur aus einem konkreten Vertrag ergeben. Da im vorliegenden Mietvertrag keine Mieterhöhung vorgesehen war, hat der Mieter Anspruch auf Schadenersatz. Die Vermieterin habe ohne Rechtsgrundlage die Miete erhöht und damit die Pflicht, die sich aus dem Mietverhältnis zwischen ihr und dem Arzt ergebe, verletzt.

ANKE THOMAS -

- Amtsgericht Spandau, Urteil vom 22.10.2009, Az. 9 C 216/og

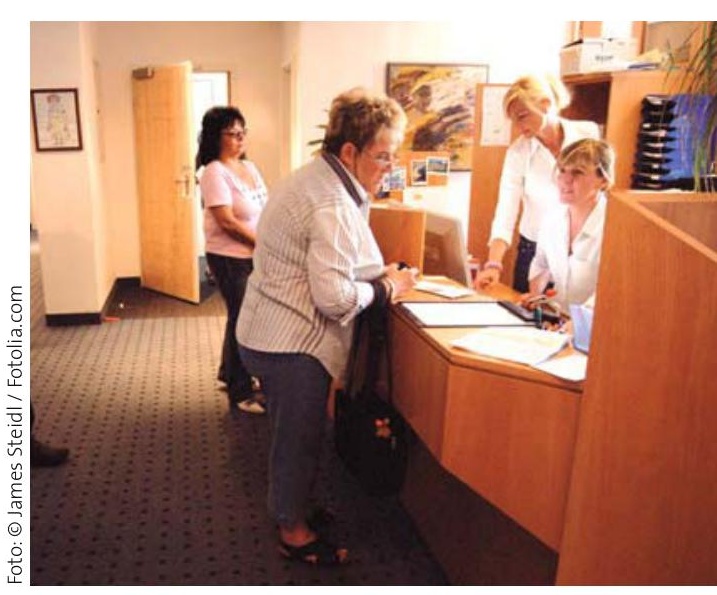

Eine Mieterhöhung ist bei Gewerberäumen nur möglich, wenn diese Möglichkeit im konkreten Mietvertrag eingeräumt wird. 